ENTERPRISE TRANSFORMATION: WHY ARE WE INTERESTED, WHAT IS IT AND WHAT ARE

\title{
THE CHALLENGES?
}

Authors

Valerie Purchase, School of Communication

University of Ulster

vc.purchase@ulster.ac.uk

Glenn Parry, Bristol Business School

University of West of England

glenn.parry@uwe.ac.uk

Ricardo Valerdi, Engineering Systems Division

Massachusetts Institute of Technology

rvalerdi@mit.edu

Deborah Nightingale, Dept. of Aeronautics \& Astronautics and Engineering Systems Massachusetts Institute of Technology

dnight@mit.edu

John Mills, Department of Engineering

University of Cambridge

jfm@eng.cam.ac.uk 
ENTERPRISE TRANSFORMATION: WHY ARE WE INTERESTED, WHAT IS IT AND WHAT ARE THE CHALLENGES?

Purchase, V., ${ }^{1}$ Parry, G., Valerdi, R., Nightingale, D. and Mills, J.

\begin{abstract}
The concept of enterprise transformation has become increasingly popular as companies recognize the need to achieve an integrated perspective within and across organizational boundaries to address complex challenges. Yet, there is little clarity concerning what constitutes an 'enterprise' or indeed 'enterprise transformation'. This paper is conceived as a step along the journey towards this clarity. There is considerable work to be done in delineating this area of interest and this paper is offered as a stimulus for debate on what constitutes enterprise transformation.
\end{abstract}

Drawing on themes from the management and systems engineering disciplines, the paper will propose four characteristics of 'enterprise' as a unit for transformation and look at why this holistic unit of analysis has become critical to businesses. The paper will also ask what constitutes transformation, and offer characterizing criteria to distinguish this magnitude of change from more incremental changes. A recent empirical case study will be examined to further elucidate challenges faced in defining, leading and transforming multi-organizational enterprises. Finally a near-term research agenda is outlined for the evolving discipline of enterprise transformation.

${ }^{1}$ Dr Valerie Purchase $(\bowtie)$

School of Communication, University of Ulster, Newtownabbey, Northern Ireland BT37 0QB

e-mail: vc.purchase@ulster.ac.uk

2 


\section{INTRODUCTION}

The Journal of Enterprise Transformation was established to 'promote a holistic approach to advancing the understanding of enterprise transformation by addressing the challenges from technical, behavioral, and social perspectives'. It is recognized that there will be considerable diversity of how disciplines and individual authors address enterprise transformation. In discussing service delivery, Purchase, Parry and Mills (2011) regard the boundaries of the enterprise as incorporating 'all inter-dependant parties involved in value delivery'. Interdependence and complexity are similarly emphasized within the following definition, 'enterprises are complex, highly integrated systems comprised of processes, organizations, information and supporting technologies, with multifaceted interdependencies and interrelationships across their boundaries', (Nightingale, 2000). A recent literature search on the term enterprise has, however, demonstrated that it 'has ranged vastly in meaning' (Valerdi, Nightingale and Blackburn, 2010), is often expressed with a variety of additional terms, and varies considerably depending upon the context and technical or practice community adopting the term.

This paper offers an approach to delineate research in this field by attempting to outline characteristics of enterprise transformation. It is hoped that the paper will stimulate discussion within the community on commonalities of focus for those academic and practitioners interested in enterprise transformation.

\section{WHY ARE WE INTERESTED IN ENTERPRISE TRANSFORMATION?}

The increasing relevance of enterprise transformation in today's organizational environment is explored within this section of the paper, before moving on to examine the nature of enterprise transformation. The authors' belief that there is an increasing need for a holistic enterprise perspective in the current environment is based on four inter-related trends: the focus on core competence requiring collaboration with other enterprise partners for value delivery; the growing requirement of customers to have holistic solutions; the increasing involvement of customers in the 'co-creation of value'; and finally, the need to work systemically with other enterprise stakeholders to both reduce costs and meet performance demands. 3 
The focus on core competence.

Organizations have always specialized internally within their businesses to achieve diverse tasks such as finance, marketing, and production with skilled and competent individuals in each area. This can lead to functional silos and the need to adopt an enterprise perspective at the corporate or firm levels. However, high costs of development has increasingly lead individual organizations as a whole to adopt a strategy of identifying and focusing on their core competence. A core competence perspective suggests that companies should differentiate between their competencies as "core", those that underpin the growth of their business and act as a differentiator (Parry et al., 2010), and "non-core" those that are not essential to compete in their chosen market (Lonsdale and Cox, 2000).

The objective of this approach is that firms should strengthen and leverage their core competencies (Ellram and Billington 2001) and outsource non-core activities. This is particularly the case when "the total costs of owning [them] are demonstrably higher than sourcing externally, and the associated risks of market failure or market power are not excessive" (Lonsdale and Cox, 2000). This trend towards the narrowing of capability and increased specialization, means that there is a need to collaborate with equally 'specialized' others to deliver value to customers, and that these enterprise partners are increasingly likely to be external. This results in highly networked enterprises, with varying partner relationships, which require transformation and management from a holistic enterprise perspective.

\section{Delivering integrated customer solutions.}

While individual organizations have been engaged in narrowing their strategic focus onto certain technologies, services or processes, customers are moving in the opposite direction by increasingly seeking total solutions and services. For example in the UK Defence sector, the Ministry of Defence are clearly moving towards seeking total solutions for maintenance and upgrade of their various platforms as evidenced in the rise of through-life support and availability contracts (Defence Industrial Strategy, 2005). To meet this customer need, organizations seek to offer total, systemic product or service solutions. Few 4 
organizations are able to provide a one-stop solution utilizing their own resources alone. This has driven the need for organizations in all sectors to collaborate in multi-organizational enterprises to deliver customer value.

Involving customers in the 'co-creation of value'.

The need to operate as an integrated and inter-dependent enterprise, is also prompted by the increasing involvement of customers in 'value co-creation'. This shift in view, where customers are part of the value creating enterprise has been highlighted by many writers. Vargo and Lusch $(2006 ; 2008)$ described the shift as moving from a traditional goods centered or 'product-dominant logic' to an emerging 'service dominant logic'. In the former way of thinking, the customer was seen as the passive recipient of goods, whereas from a service dominant perspective customers form an integral part of value delivery. Recent thinking has recognized that the customer is co-producer or co-creator of value, and that companies should encourage the customer to be proactively involved (Prahalad and Ramaswamy, 2000; 2003). They describe customers as being 'co-opted' into the design and delivery of services and suggest that the cocreation of value has shifted our ways of thinking about the boundaries between provider and customer. All parties may now be part of a common enterprise. Clearly this has increased the level of diversity and complexity in enterprise transformation and management where there may be radically differing agendas and needs for enterprise stakeholders.

\section{Collaborative cost reduction and performance improvement.}

Finally, a holistic enterprise perspective is increasingly necessary to reduce overall costs and improve value delivery. Globalization and customer demand for better products and services at lower cost has created a need for all enterprise partners to actively seek to eliminate waste and generate improvements. While individual company costs might be reduced by a single company optimizing its operations, the impact of such changes may be detrimental to the whole value system. Reductionism assumes that the enterprise is mechanical in its nature, with a local improvement giving rise to a like improvement at the 5 
systems level. However, Lipsey and Lancaster (1956) demonstrated that a system may be non-linear in nature and could achieve optimal output when certain elements are operating at sub-optimal levels. Therefore an enterprise perspective may be needed to achieve significant and sustainable cost reduction. Inter-organizational cost management techniques, including the use of target costing, may deliver significant benefits if they are adopted in an integrated manner (Slagmulder, 2002). In the same vein, performance improvement in the overall delivery of value to customers may similarly only be possible from an enterprise perspective, in order to avoid 'islands of excellence' that are locally optimized but globally sub-optimized.

This increased interest in enterprise transformation and management is also evident in many technical and practitioner communities. There is an emerging movement in industrial and systems engineering towards the application of a systems perspective to enterprises (Valerdi, Nightingale and Blackburn, 2010), and likewise within the social science community, management academics and practitioners are focusing more heavily on a wider value enterprise perspective (Prahalad and Ramaswamy, 2003; Ketchen and

Giunipero, 2004)).

\section{WHAT IS AN ENTERPRISE?}

While it would seem that an enterprise perspective is increasingly necessary in the current environment, a clear and agreed definition remains elusive. Traditionally, the term enterprise has often been used synonymously with "corporation" to describe individual firms or legal entities (Nightingale, 2000). This represents one important 'organizing perspective' which sets operational, financial, legal and indeed identity boundaries for enterprise stakeholders to work within. However, there has been a widening of this definition to incorporate other organizing perspectives or units of analysis. As Binder and Clegg (2007) highlight a number of environmental changes such as globalisation, outsourcing and virtualisation have meant that 
"more and more companies get involved in activities that are outside the boundaries of the traditional company (a single autonomous legal entity). This is typically achieved by entering into collaborative relationships or joint ventures", (p.409).

As evidence that such activities are now widely recognised, Binder and Clegg (2007) cite the European Commission (2003) definition of an enterprise as “ “... an entity, regardless of its legal form ... including partnerships or associations regularly engaged in economic activities'.

The term enterprise can therefore be applied to a single integrated company or to collections of interorganisational partners engaged in collective activities. A further valuable contribution to understanding the makeup of enterprises, is the recognition that enterprises can also be made up of the activities of subparts of different companies. Hence, only one part of a large company might be involved in a multiorganisational enterprise 'whilst other parts of the same company are operating on a completely different modus operandi with their partners and suppliers', (Binder and Clegg, 2007, p.422). Several authors draw attention to differing scales of enterprise which focus upon different goals. For example in the Aerospace and Defence context, enterprise boundaries vary considerably from being 'defined only by the specific program or product they influence to those that encompass the operations of multiple international programs', (Valerdi, Nightingale and Blackburn, 2010). So what makes these differing entities an 'enterprise'?

In an attempt to address this question, the following four characteristics are offered for the term 'enterprise'.

The term 'enterprise' is a boundary defining lens which imposes a holistic management or research perspective on a complex system of interconnected and interdependent activities undertaken by a diverse network of stakeholders for the achievement of a common significant purpose. 
In the following sections each of these interrelated characteristics are discussed in an effort to further articulate the implications of each element of this definition.

\section{A Boundary Defining Lens}

When the term enterprise is applied to an individual corporation, boundary definition can be less complex as the enterprise coincides with the boundaries of a legal entity. However, even in this situation it may be necessary for enterprise leaders or researchers to more clearly delineate enterprise boundaries. The challenge of this task becomes ever greater when resources for complex value delivery are dispersed across several organisations. The term enterprise represents a boundary defining lens which calls on all partners to view the enterprise as an integrated entity.

"It is significant when a leader in aerospace or any industry asserts that a given set of activities regardless of scale - must be viewed as an interconnected whole. That interconnected whole is an enterprise" (Murman et al., 2002, p.8).

Leaders establish a coherent enterprise perspective to encourage the achievement of common goals. This process of applying and communicating a boundary defining enterprise lens supports the constitution, management and analysis of an enterprise and is a familiar theme for scholars who recognize communication as constitutive of organizations (Taylor and Van Avery, 2000; Kuhn, 2005). As Murman et al (2002) argue 'the meaning of enterprise is not always clear. Leaders and others have to assert the interdependence of various stakeholders, and make clear that they are part of a common enterprise' (p.13). The importance of effective leadership has long been recognized in distinguishing successful from less successful organizations (Yukl, 1994); in managing change and overcoming resistance (Kotter, 1995; Kotter \& Schlesinger, 2008); and continues to be highlighted as a key variable in current studies of enterprise transformation (Rouse, 2011). This defining characteristic therefore emphasizes the important role of leadership in promoting a holistic enterprise perspective as a means of establishing coherence among a number of interdependent parties engaged in enterprise functioning and transformation. 
Similarly in a research context, enterprise transformation researchers are asked to declare the context and boundaries of the unit of analysis addressed in order to make clear the 'enterprise' under investigation. 'It is important for researchers and practitioners to develop a common understanding of enterprise analyses wherein articulating the context and boundaries provides a standard method to begin analyses and prevent miscommunication' (Valerdi, Nightingale and Blackburn, 2010). This will certainly support the researcher and reader in identifying the unit of analysis addressed, the scale of transformation, and the corresponding methods needed to facilitate transformation.

\section{A Complex System of Activities}

An enterprise perspective calls for a systemic approach to the management and alignment of activities. In other words, in order to understand and impact upon the functioning of a large and complex organizational or multi-organisational enterprise, it is necessary to view the system as a complex whole rather than seeing and optimizing parts of the enterprise. Nightingale (2000) captures the complex web of inter-related and inter-dependent processes and organizations involved in an enterprise,

"Enterprises are complex, highly integrated systems comprised of processes, organizations, information and supporting technologies, with multifaceted interdependencies and interrelationships across their boundaries," (Nightingale, 2000).

Earlier in this paper, we explored some of the drivers for this increased need for a systemic perspective including the need for greater intra- and inter-organizational collaboration in a business environment where companies are focusing on core competence; the increasing demand by customers for holistic integrated solutions; the increased involvement of customers in value delivery; and the need to move beyond optimizing parts of the value delivery system to achieve performance improvement and cost reduction.

However, despite the need for an enterprise perspective, there are significant hurdles. 
'The mindset of many managers favors individual unit thinking over cross- functional and crossfirm thinking and performance measures which emphasize individual business success rather than supply chain success' $\quad$ (Spekman and Davies, 2004)

Valerdi and Rouse (2010) agree that for many managers 'systems' thinking is not a natural act'. They argue that often the manager's work focus is narrow and based on highly specialized tasks and that they are therefore 'naturally inclined to have a limited view'. This reductionist mindset has been common amongst managers within large, single organizational enterprises, so for multi-organizational enterprises to co-ordinate toward common "enterprise goals" is likely to be even more challenging.

\section{A Diverse Network of Stakeholders}

Whether applied to a single organization or a multi-organizational entity, an enterprise perspective represents the bringing together of diverse partners. In a single organization this might involve multiple diverse functions such as marketing, operations and finance, bringing a wide variety of knowledge and capability to a common purpose. More widely, as Binder and Clegg (2007) highlight, an enterprise is likely to involve a complex web of sub-organizational units, drawn from several businesses across the whole supply chain and possibly including the customer, efficiently combining their unique core competencies in delivering complex customer solutions. While it could be argued that many parties have always been involved in value delivery within individual businesses, the greater diversity introduced by involving supply organizations and customer partners brings new challenges and may necessitate a stronger whole enterprise orientation for success. There are often more diverse stakeholders, with different cultures, different goals, and without the facilitating structures and direct authority of the single organization. This diversity is arguably more substantial when enterprises involve public and private sector partners working together to achieve complex goals (Klijn et al. 2008). Conflicting standpoints which include a lack of understanding of each partner's needs and ways of working must be counterbalanced by clearly recognizing commonality of purpose. 


\section{A Common mission}

Enterprises are defined by a common mission within specific contexts. This may be captured within a 'Core Ideology', defined as the enterprises purpose or mission and core values (Collins \& Porras 1996; Sisto, 2010). As previously mentioned, several authors draw attention to enterprises which focus upon different scales of primary mission. For example in the Aerospace and Defence context, enterprises boundaries vary considerably from being 'defined only by the specific program or product they influence to those that encompass the operations of multiple international programs', (Valerdi, Nightingale and Blackburn, 2010). In this case the enterprise is defined and enterprise boundaries are drawn by the pursuit of a common mission (e.g., Boeing 787 program) regardless of organizational affiliation. Within both 'enterprise' as a single corporation or a wider multi-organisational entity, a common mission pulls together disparate resources in pursuit of value for a variety of stakeholders including customers, shareholders and employees. As previously discussed, this characteristic of a common enterprise mission is also challenging to achieve, as functional and organizational silos, divergent training, language and culture can make aligning around common goals difficult.

\section{WHAT IS ENTERPRISE TRANSFORMATION?}

In 'enterprise transformation', therefore, the unit of transformation addressed is a clearly delineated, system of complex activities, involving a diverse network of stakeholders engaged in a common mission. But what do we mean by 'transformation'? Within the change management literature there have long been attempts to distinguish levels of magnitude of change with many writers contrasting levels of significance or extent of desired change and the impacts of such changes. These changes have been variously described as 'realignment' versus 'transformation' (Balogun \& Hope-Hailey, 2008); 'incremental' versus 'radical' (Baden-Fuller \& Stopford, 1995); 'incremental change' versus 'reinvention' (Goss, Pascale \& Athos, 1998). The following three perspectives may act as criteria for distinguishing transformation from other more modest forms of change. 
A response to radical changes in the economic, market, or social environment

Rouse (2005) argues that enterprise transformation is prompted by significant changes within the economic and market context which lead to "experienced or expected value deficiencies" requiring fundamental changes to reverse. Such changes might include for example legal or regulatory changes which impact on market competition or changing market trends. Such changes in environment 'cannot be handled within the existing paradigm and organizational routines requiring a change in the taken-forgranted assumptions and the 'ways of doing things around here', (Balogun and Hope-Hailey, 1999, p.20). They point out that for some companies incremental change is not always enough and suggest that a more fundamental shift may be needed to address the challenges faced.

\section{A fundamental alteration of context}

Several authors also allude to transformation somehow changing the context within which we operate.

Goss, Pascale and Athos (1998) suggest some 'companies do not need to improve themselves; they need to reinvent themselves. Reinvention is not changing what is, but creating what isn't', (p.85). They argue that when companies engage in reinvention, they alter their context and therefore can alter their culture and performance. The context is the sum of all past conclusions reached concerning how they operate, their relationship with customers, and their sources of past success. In discussing enterprise transformation Rouse (2005) also supports the notion of transformations altering context. He proposes that

'Enterprise transformation concerns change, not just routine change but fundamental change that substantially alters an organization's relationships with one or more key constituencies, e.g., customers, employees, suppliers, and investors. Transformation can involve new value propositions in terms of products and services, how these offerings are delivered and supported, and/or how the enterprise is organized to provide these offerings.'. 
A step change in performance

Another perspective which may be useful in distinguishing transformation relates to the magnitude of results achieved. "Rather than routine, transformation tends to be discontinuous, perhaps even abrupt. Change does not occur continually, yielding slow and steady improvements. Instead, substantial changes occur intermittently, hopefully yielding significantly increased returns to the enterprise”, (Rouse, 2005). Gerstner (2003) likewise emphasizes results in defining transformation as "a conscious and sustainable transition to a significantly higher level of business performance and organizational health, based on a fundamental shift in underlying capabilities, systems and processes".

Taking the three perspectives above, the following characteristics are offered as defining characteristics of transformation and a stimulus for further discussion on what constitutes enterprise transformation. Enterprise transformation might be described as involving a shift within a defined enterprise that is: (i) a response to radical changes in the economic, market, or social environment; (ii) a fundamental alteration of context; and (iii) a step change in performance.

\section{A CASE STUDY: KEY CHALLENGES IN ENTERPRISE TRANSFORMATION}

The authors have recently engaged in research which examines enterprise transformation within the UK Defense sector. The research was undertaken as part of a wider study on the move by traditional manufacturers and their partners, including customers, from a 'product provision' model to a 'service' focus (Oliva \& Kallenberg, 2003). The UK Ministry of Defence (MoD) is increasingly opening the support of military systems to private companies, and working in partnership with multiple organizations to deliver a support service. An early example of this move to service was offered as a transformation case study and centred on the ATTAC (Availability Transformation: Tornado Aircraft Contracts) program, a whole-aircraft 'availability' contract where BAE Systems take prime responsibility to provide Tornado aircraft with depth support and upgrades, incentivized to achieve defined levels of available aircraft, spares and technical support at a target cost. This contract was the first of its kind and required all 13 
parties to move from a product-based paradigm where there were clear targets and customer-supplier relationships to a service-based model with emergent requirements and 'value co-creation' with the MoD customer as inter-dependent partners (Vargo \& Lusch, 2008). The drivers for the adoption of this partnered approach was the need for reductions in the cost of providing this service and the belief that the service could be more effective through closer working between public and private sector partners. The detailed methodology involved in data collection and subsequent detailed analyses of the transformation are described elsewhere (Mills et al. 2009; Purchase, Parry and Mills, 2011).

For the purposes of this paper, the case study is presented to provide an illustration of some of the challenges involved in defining and transforming complex enterprises. Enterprise characteristics are discussed including the challenges involved in articulating enterprise boundaries; managing diverse stakeholders involved in service delivery; establishing a sense of common mission; and recognising interdependence within a service system. The case is then examined in relation to transformation characteristics.

\section{Articulating enterprise boundaries}

To examine the challenges inherent in this move to service, the case focused upon the transformation experienced in a single complex availability contract. Early analysis of the activities involved in delivering the ATTAC contract, suggested that the services are co-created through a complex set of multiorganisational interactions. The decision was therefore taken to adopt a holistic enterprise research perspective in examining this transformation, rather than an 'organizational transformation' perspective focusing only on the main industry provider. The boundaries of the enterprise transformation were therefore regarded as incorporating 'all inter-dependant parties involved in value delivery' (Purchase, Parry and Mills, 2011). However, articulating enterprise boundaries would seem to be a key challenge for enterprise transformation and management. 
Interviews with enterprise partners highlighted challenges encountered in 'seeing the full picture' of activities and organisational actors necessary for service delivery; and hence establishing agreed boundaries for the ATTAC enterprise.

Current mapping tools were found to be inadequate in capturing and communicating enterprise boundaries. During the case study compilation, an 'enterprise imaging tool' was created based on a development of 'service blueprinting' methodology (Shostack, 1984; Zeithamel et al., 2009) in an attempt to map the ATTAC program. The detail of this enterprise mapping process is presented and evaluated elsewhere (Mills, Parry and Purchase, 2011a), however, a simplified version of the resulting image (figure 1) highlights main processes and partners involved in the ATTAC program. Key service processes are illustrated as taking place in the ATTAC 'front office' (Zeithamel et al., 2009) with an indication of the complex network of organizational stakeholders involved in the management and staffing of these processes. Within the next section outlining the complex network of stakeholders involved in value cocreation, a description of key actors and activities is provided.

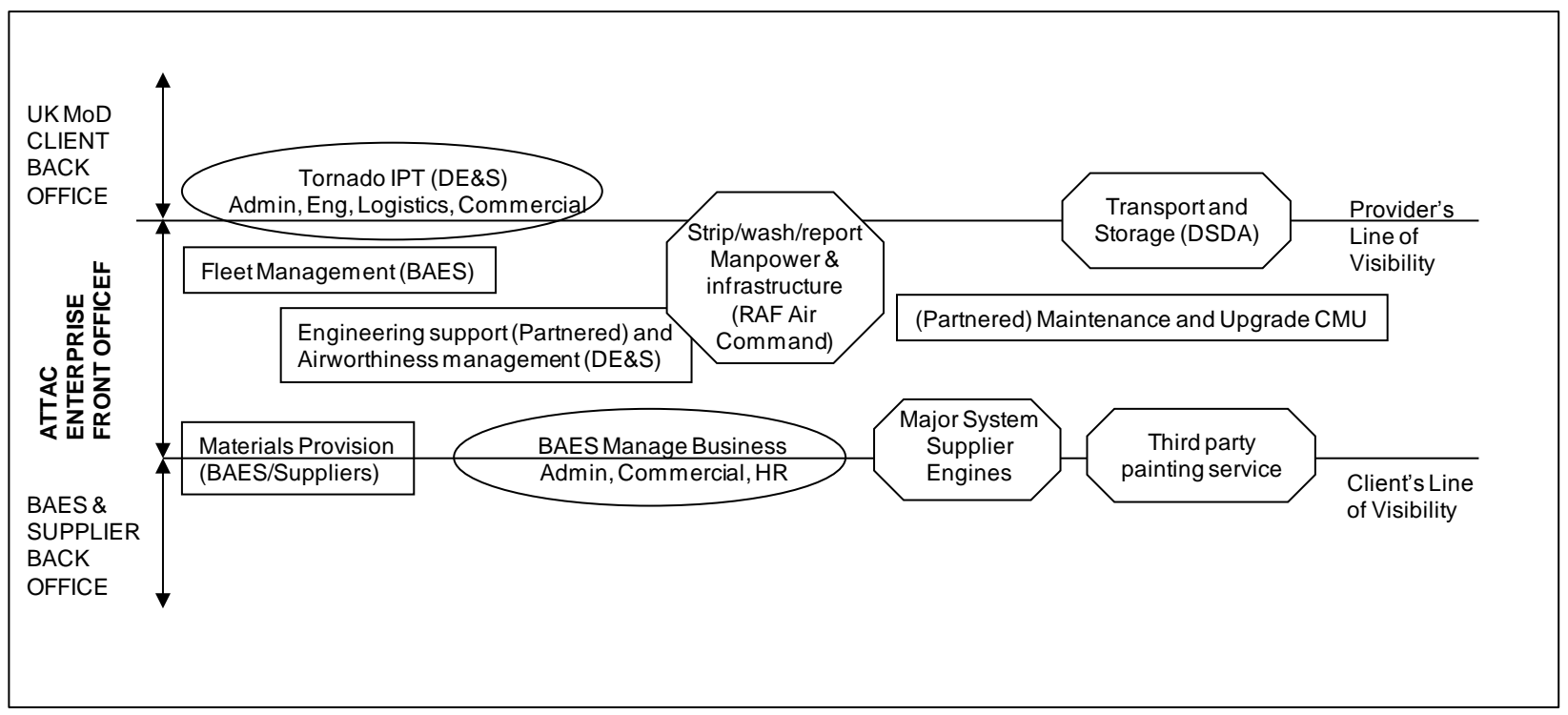

Figure 1 Simplified Enterprise Image - ATTAC showing key service processes and organizational involvement (Adapted from Mills, Parry and Purchase, 2011a) 


\section{Managing diverse enterprise stakeholders}

The ATTAC program certainly represents a complex engineering service which is co-created by a complex and diverse web of industry and customer enterprise partners. The partners comprise a variety of on-base organizations at a Royal Air Force (RAF) base located in Marham, UK, supported by off base organizations acting in partnership (Mills et al, 2009).

From the time an aircraft is recalled for servicing, to the time it becomes available again for further duties, a wide variety of organizations and sub-organizational units have collaborated in providing this 'availability service'. BAE Systems (BAES) are the prime service provider and perform many key roles either directly or through managing RAF personnel to deliver their services. Managed by BAES, a 'fleet management' organization provides the planning activities that translate the RAF Squadron requirements for Tornado's into the schedule of aircraft through the maintenance hangers. BAES then manage the hanger activity, staffed by both BAES and the customer RAF Air Command personnel, where the operational services are delivered.

Engineering support is managed by BAES based at both RAF Marham and their other sites. This activity resolves technical queries and safety issues and is similarly staffed by RAF and industry personnel. The Defence Equipment \& Support (DE\&S) managed Tornado Project Team (PT) contains solely RAF staff covering administration, engineering, logistics, and commercial support of ATTAC on behalf of the UK Ministry of Defence (MoD). This organization is responsible for airworthiness and procurement and monitoring of contract performance.

Following maintenance, the aircraft may need to be repainted. A third party company provides a painting service, one of the later inline processes in the delivery of maintained aircraft and therefore a significant dependency. None of the support services would be possible without the variety of sub-organizations within RAF Air Command who both provide and are responsible for the hangars themselves, and their electrical / hydraulic power and information technology infrastructure. 16 
A number of the supply chain organizations are also a critical part of this multi-organizational service enterprise. Spare components and systems are provided by both the prime and sub-tier supply organizations which may deliver to the prime, to the customer or directly to the RAF squadron for aircraft on duty. Finally, a further organization, the Defence Storage and Distribution Agency (DSDA), is the sole provider of transport and off base storage of Tornado parts. The ATTAC program faced significant challenges of cultural diversity as public and private sector organisations began to work closely together. This may raise enterprise transformation and management. Are such culturally diverse enterprises more difficult to manage and transform than corporate enterprises? There is certainly strong evidence for significant challenges in managing public-private partnerships (Klijn et al., 2008).

Within a supply chain it is often the prime who plays a lead role in managing this 'extended enterprise' (Coughlin, et al., 2003), however, when customers are also key enterprise partners issues of power and traditional adversarial customer-supplier relationships complicate the adoption of shared leadership (Lamming, 1996; Spekman and Davies, 2004). This may have affected enterprise partners in the initial stages of enterprise transformation in that enterprise activities tended at this time to be managed as 'separate activities' rather than as a jointly managed whole enterprise. Enterprise thinkers must move beyond identification of dyadic buyer/supplier dependence and acknowledge that there are reciprocal dependencies between enterprise partners.

\section{Establishing a sense of common mission}

During the ATTAC transformation, the enterprise partners experienced a maturing in their sense of common enterprise purpose. The process involved an initial identification and focus on achieving contracted services and key performance indicators. In the early stages of contract implementation, this was largely targeted on shaping and measuring the performance of the prime contractor, and neglected the role of the customer organizations in value delivery. However, as the service transformation progressed 
all partners began to align around broader service goals. This process was described as a 'circling of the wagons' and pulling together to achieve common goals.

The existence of common goals did not, however, preclude or make partners blind to the diverse needs and goals of individual stakeholders (Mills, Parry and Purchase, 2011b). All parties were aware that the industry partners also had goals relating to securing current and future business given that few new manned air defense platforms were planned in the foreseeable future. There was also recognition that a key strategic goal for Industry partners was the successful implementation of the ATTAC programme as a means of attracting further contracts, thus, enhancing market share, and maintaining important customer relationships. Likewise industry partners began to more fully understand their Defense customers' need to provide respite from frontline duty and development for their service personnel. Such factors point to the need in enterprise transformation research and practice to understand more fully the complex interplay of enterprise and individual partner goals; the extent to which conflicting goals need to be acknowledged; the strains which can be placed on enterprise leaders and partner organisations as they pursue both 'enterprise' and 'individual partner' goals. The identification of individual stakeholder values, along with the creation of a multi-stakeholder value proposition has been proposed as a key strategy for enterprise leaders before they begin their transformation (Murman, et al., 2002).

\section{Recognizing the systemic nature of enterprises}

The ATTAC services are co-created by a complex and inter-dependent multi-organizational service enterprise, which must align and coordinate activities to support delivery of the service for the RAF. The enterprise partners cannot achieve their aims independently. The hanger maintenance activities are managed by BAES and resourced by a combination of BAES, RAF and others. Maintenance activities are only made possible through a number of RAF provided services including electrical / hydraulic power and information technology infrastructure for the hanger buildings. The engineering support again provided by both BAES and MoD personnel is necessary to resolve technical queries and safety issues, before 
maintenance and upgrade can occur. Finally, the service enterprise includes the Defence Equipment \& Support managed Tornado Integrated Project Team (IPT) containing solely RAF staff covering administration, engineering, logistics, and commercial support of ATTAC on behalf of the Ministry of Defence. This organization is responsible for airworthiness and procurement and monitoring of contract performance, again a highly inter-dependent part of the complex service system. This brief overview gives some indication of the systemic nature of the ATTAC enterprise inter-relationships and interdependencies at the operational level.

This acknowledgement of the systemic nature of the enterprise was perhaps one of the greatest challenges encountered by all stakeholders in the ATTAC service enterprise transformation. There was evidence in the case study that in the early bid development stages for the ATTAC contract a more holistic perspective was taken among the diverse set of partners. At this early stage, BAES and the MoD seem to have worked closely from what might be described as an integrated 'service enterprise' perspective, where they attempted to understand and co-design what might be involved in a partnered process of service delivery. However, this holistic perspective may have been at least partially lost once the programme implementation was underway. Realities began to be faced and some resistance experienced as the partners began the necessary transformation to new ways of working. During this difficult initial implementation period the various enterprise partners seem to have reverted to a 'single entity' perspective and traditional buyer/supplier relations rather than holistic 'enterprise' thinking. This sense of fragmentation was evident not only between but within organisations as well. Such divisions were felt between on-base staff who directly managed the delivery of service and their supporting functions within their parent organisations, who seemed not to understand the changing needs and timescales under which the front-line service providers now operated.

As the enterprise transformation progressed, industry and their Defense partners began to once again recognise that they were inter-dependent in the 'co-creation of value' (Prahalad and Ramaswamy 2000 \& 
2003) and how this created a need to 'co-manage' the enterprise and work collaboratively to improve service delivery. At later stages, within the ATTAC transformation an inter-organizational management team was formed to more strongly enable an 'enterprise perspective' to be taken on performance improvement, service redesign, and to address critical problem-solving.

\section{Is this enterprise 'transformation'?}

Enterprise transformation has been described as a fundamental shift within a defined enterprise that is a response to radical changes in the economic, market, or social environment; a fundamental alteration of context; and a step change in performance. Each of these propositions is now discussed in relation to the case study.

Within a number of sectors including Defence, a radical change is taking place in the definition of customer value. This is evidenced through the customer demand for capability, availability, operability and affordability (Ward \& Graves, 2007), and represents a shift away from a product to a service based model of value delivery.

Clients want more value and this value is connected to the use and performance of systems; they want solutions more than just products or services; they want to take advantage of their supplier's know-how and not just their product; they want an integrated and global offering and are reluctant to do business with several suppliers; finally, they want customized relationships (Mathieu, 2001, p458).

The UK MoD are likewise changing their definition of customer value - emphasising availability and capability for future contracts. In a significant shift of policy, there is an increasing willingness from $\mathrm{MoD}$ to transfer support of Defence assets to industry (Defence Industrial Strategy, 2005) driven in part by the need for significant cost reduction without a reduction in value delivered. The ATTAC program was developed in response to these challenges which demanded a radical transformation in the business model, relationships, management accountability and ways of working from all parties involved. 
This case would also seem to represent a fundamental alteration in context from what has gone before for all enterprise partners. As highlighted earlier in this paper, the context is the sum of all past assumptions concerning how an enterprise should operate, their relationship with customers, and their conclusions concerning sources of past success. As Mathieu (2001) points out, the move from a product- to a servicebased business model constitutes a significant shift in assumptions which are not without risk.

"The most ambitious service strategies are also the riskiest because they have to support multiple costs associated with their implementation and challenges deeply embedded assumptions within the business", (Mathieu, 2001, p.471).

The ATTAC program incorporating each of the organizational entities involved in delivering and supporting the program would appear to be undergoing an ambitious transformation. For the ATTAC partners this has meant not just a change of practices and processes but a fundamental rethinking of many factors including the relationships with the customer, cost structures and goals, organizational culture and operational boundaries.

The interview analysis with both industry and MoD partners provided evidence from the participants' perspective on the magnitude of change and the initial lack of recognition of the scale and complexity involved. There was also recognition that the service enterprise transformation process was significantly more complex than transforming a single organization.

Finally, the transformation underway within the case study represents efforts to secure 'a step change' in relation to cost savings and improved performance. The ATTAC contract offered savings of at least $£ 510$ million over the first 10 years, with its success recognised by the National Audit Office (NAO, 2007). Savings arose from reductions in RAF and civilian personnel and the improvements a commercial organization was expected to bring to the task (Mills et al, 2009). In the recent independent UK MOD "Review of Acquisition" by Bernard Gray (2009) he comments that availability contracts "appear to have 
delivered very significant savings over historical unit cost rates". However, total savings realized over the contract life cannot be evaluated at this stage.

This enterprise transformation case study has demonstrated some of the challenges and complexities of transforming a complex system of inter-dependent activities undertaken by a network of diverse multiorganizational stakeholders. Clearly many questions remain to be answered within this area of study, providing a rich environment for academic enquiry inspired by real world challenges. It will be necessary to further question not only the validity of the characteristics that define enterprise transformation but also the robustness of the criteria. As more case studies are performed, we will also broaden our understanding of the contextual influences on enterprise transformation.

\section{CONCLUSION AND FUTURE DIRECTIONS}

The Journal of Enterprise Transformation has been created as a vehicle to support 'an emergent community of practitioners and researchers that are working to define enterprise principles and put them into action', (Nightingale and Valerdi, 2009). This paper argued that there is an increasing need for an integrated enterprise perspective to address value delivery in today's environment. There are, however, many challenges faced in taking an enterprise perspective not least of which is the absence of a common definition, language and enterprise level tools to describe an enterprise perspective, boundaries, processes, and roles. This paper has attempted to contribute to ongoing efforts to characterize and discuss enterprise transformation. The characteristics offered make no claim to be either comprehensive or the optimum set of defining features but rather are offered as a starting point for analysis and discussion. Other frameworks such as 'complex adaptive systems' (Holland, 1999; Fromm, 2004) and 'enterprise architecture' (Ross et al., 2006), for example, are also recognized as potentially fruitful sources of concepts and language for enterprise transformation.

Finally, beyond the quest for greater clarity in defining attributes and challenges for enterprise transformation, there are a number of near-term needs for the evolving broader discipline of enterprise 22 
transformation. These needs are driven by the diverse nature of the study of enterprise transformation, the need to accelerate scholarly exchange, and to support ongoing enterprise transformation. In the spirit of this special issue on the intellectual agenda of enterprise transformation, the following four critical needs are identified:

1. Classification and synthesis of enterprise transformation theories. The number and diversity of existing theories of enterprise transformation pose a series of challenges for mapping the state of the art. A classification and synthesis of the various theories would improve the current situation of disconnected theories and provide a complete picture of the field. This could be done through a meta-study comparing different theories of transformation and their effectiveness, assumptions, and conditions in which they work well.

2. More empirical testing of enterprise transformation theories and tools. The legitimacy of this field rests on the ability to demonstrate the practical value of transforming enterprises. More empirical studies are needed to demonstrate the internal and external validity of theories and tools that enable transformation.

3. Longitudinal studies of enterprises to determine the effectiveness of transformation methods. A specific type of study that is critical for advancing the body of knowledge of enterprise transformation is a longitudinal study. Repeated observations over long periods of time will help identify both on-going processes and long-term effects of transformation in different settings.

4. Refinement of research methods for enterprise transformation. In order to support an increase in empirical tests there must be a mature set of research methods that are valid, reliable, and scaleable to different units of analysis. It is important to understand the benefits and limitations of case studies, grounded theory and simulations for doing research in enterprise transformation so that the most appropriate method can be applied to certain situations. The sign of a mature discipline is the existence of mature methods for performing research that can help perform, communicate and evaluate empirical studies. The diversity of this community has the benefit of 
drawing from engineering, management, and the social sciences which could result in a multidisciplinary suite of tools that can be utilized to help advance the state of the art.

Future contributions within this journal may enable different disciplines to bring greater clarity to key concepts, move the proposed research agenda forward in conjunction with their own objectives of transforming enterprises; and contribute to the development of this area of study.

\section{ACKNOWLEDGMENTS}

The authors would like to acknowledge and thank BAE Systems, and the ATTAC program industry and UK MoD partners for their engagement with our work. This research was supported by BAE Systems and the UK Engineering and Physical Sciences Research Council, and by the Lean Advancement Initiative at MIT.

\section{REFERENCES}

Baden-Fuller, C. and Stopford, J. (1995) Rejuvenating the Mature Business, Routledge, London.

Balogun, J. and Hope-Hailey, V. (2008) Exploring Strategic Change, Edition 3. Prentice Hall, London.

Barney, J. (1991) Firm resources and sustained competitive advantage. Journal of Management, 17 (1): $99-120$.

Binder, M. and Clegg, B. (2007) Enterprise Management: A new frontier for organisations. International Journal of Production Economics, 106 (2): 409-430.

Bryman, A. (2008) Social Research Methods, Oxford University Press, Oxford.

Casciaro, T., and Piskorski, M. J. (2005) Power imbalance, mutual dependence and constraint adsorption: A close look at resource dependence theory. Administrative Science Quarterly, 50 (2): 167-199.

Collins, J. C. \& Porras, J. I. (1996). “Building Your Company’s Vision”, Harvard Business Review, SeptemberOctober, 65-77.

Coughlin, P., Coghlan, D., Lombard, F., Brennan, L., McNichols T., and Nolan, R. (2003) Managing collaborative relationships in a period of discontinuity. International Journal of Operations \& Production Management, 23 (10): 1246-1259.

European Commission, 2003. Commission recommendation of 6 May 2003 concerning the definition of micro, small and medium-sized enterprises. Official Journal of the European Union C 1422, L124/36-41

Ellram, L. and Billington, C. (2001) Purchasing leverage considerations in the outsourcing decision. European Journal of Purchasing \& Supply Management. 7: 15-27.

Fromm, J (2004) The emergence of complexity. Kassel Univ. Press

Gebauer, H., Fleisch, E. and Friedli, T. (2005) Overcoming the Service Paradox in Manufacturing Companies, European Management Journal, 23 (1): 14-26.

Gerstner, L. (2003) Who Says Elephants Can't Dance?: How I Turned Around IBM, HarperCollins, Glasgow. 
Goss, T, Pascale, R. and Athos, A. (1998) The Reinvention Roller Coaster: Risking the Present for a Powerful Future. Harvard Business Review on Change, Harvard Business School Press, Boston, MA.

Gray, B, (2009) Independent Review of Acquisition for the Secretary of State for Defence, MOD: London. Available: www.mod.uk

Holland, J H (1996) Hidden order: How adaptation builds complexity. Addison Wesley, Reading, MA, 1996.

Hope-Hailey, V., and Balogun, J. (2008) Exploring Strategic Change, ed. 3, Prentice Hall.

Ketchen, D.J., Giunipero, L.C., (2004) The intersection of strategic management and supply chain management. Industrial Marketing Management 33, 51-56.

Klijn, E. H., Edelenbos, J., Kort, M., and van Twist, M. J. W. (2008) Facing management choices: an analysis of managerial choices in 18 complex environmental public/private partnership projects. International Review of Administrative Sciences, 74: 251- 282.

Kotter, J. P. (1995) Leading Change: Why Transformation Efforts Fail. Harvard Business Review, 73 (2): 59-67.

Kotter, J. P. and Schlesinger, L. A. (2008) Choosing Strategies for Change. Harvard Business Review, 86 (7/8): 130139.

Kuhn, T. (2005) A communicative theory of the firm: Developing an alternative perspective on intra-organizational power and stakeholder relationships. Organization Studies, 29(08/09): 1227-1254.

Lamming, R. C. (1996) Squaring Lean Supply with Supply Chain Management. International Journal of Operations \& Production Management, 16(2): 183-196.

Lipsey, R.G. \& Lancaster, K (1956-1957). The General Theory of Second Best. The Review of Economic Studies, 24(1), pp. 11-32

Lonsdale, C. and Cox, A. (2000) The historical development of outsourcing: the latest fad? Industrial Management \& Data Systems 100 (9): 444-450.

Mathieu, V. (2001) Service strategies within the manufacturing sector: benefits, costs and partnership. International Journal of Service Industry Management, 12 (5): 451-475.

Mills, J., Crute, V., and Parry, G. (2009) Enterprise imaging: visualising the scope and complexity of large scale services. QUIS 11 - The Service Conference, June 11th-14th, Wolfsburg Germany.

Mills J., Parry, G., and Purchase, V. (2011a) Enterprise Imaging: visualising the scope and dependencies in large scale service enterprises. In Ng, Parry, Wild, McFarlane, Tasker (eds) Complex Engineering Service Systems: Concepts and Research, Springer: London.

Mills J., Parry, G., and Purchase, V. (2011b) Towards Understanding the Value of the Client's Aspirations and Fears in Complex, Long-term Service Contracts. In Ng, Parry, Wild, McFarlane, Tasker (eds) Complex Engineering Service Systems: Concepts and Research, Springer: London.

Ministry of Defence (MoD) UK (2005) Defence industrial strategy: Defence white paper, command 6697. Presented to UK Parliament by the Secretary of State for Defence. December 2005.

Murman, E, Allen, T. et al. (2002) Lean Enterprise Value: Insights from MITs Lean Aerospace Initiative, New York, Palgrave.

NAO (2007) Transforming logistics support for fast jets, Report by the Comptroller and Auditor General, HC825 Session 2006-2007, 17th July 2007, NAO: London. 
Nightingale, D. J. (2000) Lean enterprises - A Systems Perspective. MIT Engineering Systems Division Internal Symposium, Cambridge, MA, USA, 341-358.

Nightingale, D. J. and Valerdi, R. (2009) 'Prospectus for the Journal of Enterprise Transformation'.

Oliva, R. and Kallenberg, R. (2003) Managing the Transition from Products to Services. International Journal of Service Industry Management, 14 (2): 160-172.

Parry, G., Mills, J., Turner, C. (2010) "Lean competence: integration of theories in operations management practice", Supply Chain Management: An International Journal, 15(3): 216-226

Pfeffer J., Salancik G. R. (1978) The External Control of Organizations: A Resource Dependence Perspective, Harper and Row, New York.

Prahalad, C. K. and Ramaswamy, V. (2000) Co-opting customer competence. Harvard Business Review 78 (1): 79 87.

Prahalad, C. K. and Ramaswamy, V. (2003) The new frontier of experience innovation. MIT Sloan Management Review, 44 (4): 12-18.

Price, C. (2008) How to transform large complex companies, McKinsey Seminar Series, University of Bath School of Mangement, 25th April.

Purchase, V., Parry, G. and Mills, J. (2011) Service Enterprise Transformation. In Ng, Parry, Wild, McFarlane, Tasker (eds.) Complex Engineering Service Systems: Concepts and Research, Springer: London.

Ross J., Weill P., and Robertson D., (2006) Enterprise Architecture as Strategy: Creating a Foundation for Business Execution. Harvard School Business Process.

Rouse, W.B. (2005) A theory of enterprise transformation. Systems Engineering, 8 (4)|: 279- 295.

Rouse, W.B. (2011) Necessary competencies for transforming an enterprise. Journal of Enterprise Transformation, 1 (1).

Shostack L (1984) Designing services that deliver. Harvard Business Review (Jan-Feb): 133-139

Sisto, G., (2010) Assessing Stakeholder Salience through the View of Lean Enterprise Transformation, MSc Thesis submitted to the Department of Aeronautics and Astronautics, MIT, June 2010.

Slagmulder, R. (2002) Managing costs across the supply chain. In Seuring, S. and Goldbach, M. (Eds) Cost Management in Supply Chains, Physica-Verlag, New (Eds) Cost Management in Supply Chains, Physica-Verlag, New York.

Spekman R.E. and Davies E.W. (2004) Risky business: expanding the discussion on risk and the extended enterprise. International Journal of Physical Distribution \& Logistics Management, 34 (5): 414-43.

Taylor, J. R. and Van Avery, E. J. (2000) The Emergent Organisation: Communication as Its Site and Surface, New Jersey, Laurence Erlbaum Associates.

Valerdi, R., Nightingale, D. J. and Blackburn, C., (2008) Enterprises as Systems: Context, Boundaries and Practical Implications. Information, Knowledge and Systems Management, 7(4): 377-399.

Valerdi, R. and Rouse, W. B. (2010) When systems thinking is not a natural act. $5^{\text {th }}$ IEEE Systems Conference, San Diego, CA, April.

Vargo, S. L. \& Lusch, R. F. (2006) Service-dominant logic: continuing the evolution. Journal of the Academy of Marketing Science, 36: 1-10. 
Vargo, S.L. \& Lusch, R.F. (2008) Service-dominant logic: What it is, what it is not, what it might be. In Lusch R. F. And Vargo, S. L. (Eds.), The Service-dominant Logic of Marketing: Dialog, Debate and Directions (pp. 43-56).

Armonk NY: ME Sharpe.

Ward Y. and Graves A. (2007) Through-life management: the provision of total customer solutions in the aerospace industry. International Journal of Service Technology and Management, 8 (6): 455-477.

Williamson, O. E. (1981) "The economics of organization: The transaction cost approach". American Journal of Sociology, 87(3): 548-577.

Yukl, G. (1994) Leadership in Organisations ( $3^{\text {rd }}$ edn). Prentice-Hall: Englewood Cliffs, NJ.

Zeithamel V. A., Bitner M. J., Gremier D. D. (2009) Services Marketing: Integrating Customer Focus Across the Firm ( $5^{\text {th }}$ Edition). McGraw-Hill, NY. 